Cardiac CT Imaging 
Matthew J. Budoff and Jerold S. Shinbane Editors Associate Editors Stephan Achenbach, Paolo Raggi, and John A. Rumberger

\section{Cardiac CT Imaging}

\section{Diagnosis of Cardiovascular Disease}

With 299 Figures

including 168 Color Plates

Springer 


\section{Editors:}

Matthew J. Budoff, MD, FACC, FAHA

Los Angeles Biomedical Research

Institute at Harbor-UCLA

Medical Center

Torrance, CA

USA
Jerold S. Shinbane, MD, FACC

Division of Cardiovascular

Medicine

University of Southern California

Keck School of Medicine

Los Angeles, CA

USA

Paolo Raggi, MD

Department of Cardiology

Tulane University School of Medicine

New Orleans, LA, USA

John A. Rumberger, PhD, MD

Cardiovascular Disease

The Ohio State University

Dublin, OH, USA

British Library Cataloguing in Publication Data

Cardiac CT imaging : diagnosis of cardiovascular disease

1. Heart - Tomography 2. Cardiovascular system - Diseases - Diagnosis

I. Budoff, Matthew J. II. Shinbane, Jerold III. Rumberger, John A. IV. Raggi, Paolo V. Achenbach, S.

(Stephan)

$616.1^{\prime} 2^{\prime} 075722$

ISBN-10: 1846280281

Library of Congress Control Number: 2005928171

ISBN-10: 1-84628-028-1 e-ISBN 1-84628-146-6

ISBN-13: 978-1-84628-028-3

Printed on acid-free paper

(c) Springer-Verlag London Limited 2006

The software disk accompanying this book and all material contained on it is supplied without any warranty of any kind. The publisher accepts no liability for personal injury incurred through use or misuse of the disk.

Apart from any fair dealing for the purposes of research or private study, or criticism or review, as permitted under the Copyright, Designs and Patents Act 1988, this publication may only be reproduced, stored or transmitted, in any form or by any means, with the prior permission in writing of the publishers, or in the case of reprographic reproduction in accordance with the terms of licences issued by the Copyright Licensing Agency. Enquiries concerning reproduction outside those terms should be sent to the publishers.

The use of registered names, trademarks, etc. in this publication does not imply, even in the absence of a specific statement, that such names are exempt from the relevant laws and regulations and therefore free for general use.

Product liability: The publisher can give no guarantee for information about drug dosage and application thereof contained in this book. In every individual case the respective user must check its accuracy by consulting other pharmaceutical literature.

Printed in Singapore. $\quad(\mathrm{BS} / \mathrm{KYO})$

$\begin{array}{lllllllll}9 & 8 & 7 & 6 & 5 & 4 & 3 & 2 & 1\end{array}$

Springer Science+Business Media

springeronline.com 


\section{Dedication}

If I have been able to see further, it was only because I stood on the shoulders of giants.

Sir Isaac Newton

To fully appreciate the current stature of cardiac computed tomography (CT) as both a radiological procedure and cardiology tool, one must acknowledge the pioneering efforts of the original luminaries in the field. British-born visionary David G. King was the lead engineer in the development of the original CT scanner that resulted in a Nobel Prize for his colleague, Sir Godfrey Hounsfield. Their combined "broad shoulders" became a springboard for the worldwide development and commercial success of CT. King introduced CT imaging to the United States, installing and commissioning a "head scanner" at the Mayo Clinic in 1973. David King's scientific career began at the EMI Research Labs in Middlesex (UK). It ended at General Electric, after he shepherded electron beam tomography at Imatron. He became the intellectual centerpiece of a fertile "brain trust," which stimulated the research and coordinated the clinical activities of a new generation of cardiologists and radiologists. The authors dedicate this edition to David King, an inspirational friend and the "father of coronary calcium imaging."

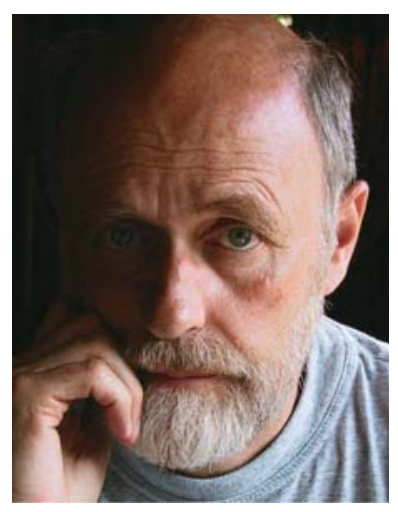

David G. King (1946-2004)

Scientist, Mentor, Friend 


\section{Foreword}

Cardiac CT has finally come of age. After nearly 30 years of development and growth, tomographic X-ray is being embraced by cardiologists as a useful imaging technology. Thirty years ago, Doug Boyd envisioned a unique CT scanner that would have sufficient temporal resolution to permit motion-artifact-free images of the heart. In the late 1970s I had the good fortune to work closely with Dr. Boyd, Marty Lipton, and Bob Herkens who had the vision to recognize the potential of CT imaging for the diagnosis of heart disease. In the early 1980s, when electron beam CT became available, others, including Mel Marcus, †John Rumberger, Arthur Agatston, and †Dave King, were instrumental in making clinical cardiologists aware of the potential of cardiac CT.

In 1985 several investigators recognized the potential of cardiac CT for identifying and quantifying coronary artery calcium. Now, 20 years later, there is wide recognition of the value of coronary calcium quantification for the prediction of future coronary events in asymptomatic people. It has been a long and arduous road, but finally widespread screening may significantly reduce the 150,000 sudden deaths and 300,000 myocardial infarctions that occur each year in the United States as the first symptom of heart disease.

In the late 1970s, it was thought that a $2.4-\mathrm{sec}$ scan time was very fast CT scanning. With the development of electron beam technology, scan times of $50 \mathrm{msec}$ became possible giving rise to terms such as fast CT, ultrafast CT and RACAT (rapid acquisition computed axial tomography). Now, with the development of multidetector scanners capable of $64,128,256$, and beyond simultaneous slices, spatial resolution is approaching that of conventional cineangiography and the holy grail, non-invasive coronary arteriography, appears attainable.

In this book, Drs. Matt Budoff and Jerold Shinbane, preeminent leaders in the field of cardiac CT, have described the many and varied uses of the technology in the diagnosis of cardiovascular disease. The book clearly documents that cardiac CT has not only arrived but has become a very valuable and potent diagnostic tool.

Bruce H. Brundage, MD MACC Medical Director

Heart Institute of the Cascades Professor of Medicine Emeritus UCLA School of Medicine 


\section{Preface}

Since its introduction in the early 1970s, computed tomography (CT) has become a robust modality to evaluate extracranial, thoracic, and abdominal vascular distributions. It has become a gold standard to non-invasively image the aorta, pulmonary arteries, great vessels, renal and peripheral arteries. However, cardiac anatomy evaluation with this modality was not possible, due to rapid cardiac motion and slow image acquisition times. Since the introduction of the first dedicated cardiac CT scanner, the electron beam CT (EBCT), the diagnosis and workup of cardiac structures has become possible. The lack of movement of the X-ray source allowed for images at a rate of 20 per second 100 times faster than conventional CT at that time. Dr. Douglas Boyd, the inventor of EBCT, created this technology specifically with cardiac imaging in mind, and first published clinical data in 1982 [1]. However, limited reimbursement, high cost of acquisition, and very limited industry support kept this technology from expanding. The number of EBCT scanners in operation at any time never exceeded 100 worldwide, and physician exposure to the technology was very limited. Despite these hurdles, functional cardiac analysis (wall motion, cardiac output, wall thickening, and ejection fraction), perfusion imaging, non-invasive angiography, and coronary calcium assessment were validated, each with at least ten years of experience. To date, over 1000 scientific papers have been published in English, and three scientific statements from the American Heart Association have been written specifically on this modality. With the advent of helical CT in the mid-1990s and multidetector CT (MDCT) in 1999, the widespread availability of scanners to thousands of centers created a marked increase in utilization of and interest in cardiac CT. By 2004, three professional societies were vying for membership of potential cardiac CT physicians, and guidelines and credentialing standards were developed at a record pace.

Despite coronary calcium reports since 1989, and non-invasive coronary angiographic imaging reports with EBCT since 1995 [2], these applications did not gain widespread appeal until studies with MDCT became available. The preliminary studies (with subsecond single slice "helical" CT), had very limited cardiac applications and significant motion artifacts. The comparisons to EBCT were modest at best, and most investigators were quite concerned about applying the results of helical CT to clinical patients [3]. The early exposure MDCT, specifically the 4-slice scanner, was also disappointing with limited temporal resolution, volume coverage, collimation, and $z$-axis imaging. Due to the rapid coronary motion and limited scan speeds available with these early scanners, accurate and reliable imaging of the heart and coronary arteries has been significantly limited [4]. Diagnostic accuracy for cardiac 4-slice MDCT angiography, the most promising new application of these machines, was severely limited. Several studies reported diagnostic rates of only $30 \%$, mostly due to cardiac motion [5]. However, evolution of MDCT with increased detectors, allowing for thinner slices and improved spatial resolution, has made this a most robust technology. Cardiac CT (with either MDCT or EBCT) offers several advantages over other diagnostic methodologies and is quite complementary to more common or traditional tests performed today. Clearly, the ability to see the lumen and vessel wall adds quite a lot to the assessment of the cardiac patient. Yet cardiac CT does not readily afford functional assessment of the patient under stress (exercise), and that information, garnered most commonly with treadmill testing, stress thallium, or echocardiography, adds vital information to the cardiac assessment. Thus, cardiac CT 
has been seen as a mostly complementary modality, adding anatomic information to the functional data acquired with stress testing.

Magnetic resonance imaging garnered quite a bit of interest in the early 1990s with the promise of a non-invasive angiogram with high accuracy. However, the next decade brought little improvement in the diagnostic accuracy of this technique, most likely due to limitations in slice thickness, temporal and spatial resolution. As compared to MRI, EBCT and MDCT allow for higher spatial and temporal resolution. The ease of use and robustness allow for fairly easy application to a variety of cardiac diagnoses. This book will highlight the vast array of cardiac (and vascular) applications of CT, updating the reader on the methodology employed by a variety of experts with a cumulative 100 or more years of cardiac CT experience.

We are forever indebted to the experts (both cardiologists and radiologists) who have spent the last 10 to 20 years of their lives dedicated to studying and publishing in this particular field of interest. Some of the experts who originated this work in the mid1980s and allowed us to progress to where we are today include Bruce Brundage, William Stanford, Ralph Haberl, Geoff Rubin, Robert Detrano, Warren Janowitz, Arthur Agatston, John Rumberger, Marty Lipton, and Ruping Dai. This is clearly a very incomplete list, yet these are some of the early investigators who had to literally fight against a medical community that thought cardiac CT posed a threat to their more traditional tests. There has been significant controversy regarding cardiac CT over the years, with raging debates at national meetings and policies by the professional organizations sometimes swayed against the technology more by emotion than science.

The pathway that cardiac CT had to endure over the last 20 years is reminiscent of a quote by Arthur Schopenhauer. He stated:

All truth passes through three stages.

First, it is ridiculed.

Second, it is violently opposed.

Third, it is accepted as being self-evident.

A prominent cardiologist and past president of the American College of Cardiology recently told me that he thought some of the early investigators in the 1980s were clearly out of their mind when suggesting widespread use of cardiac CT, whether for coronary calcium assessment as a "mammogram of the heart," or CT angiography as a possible replacement for some conventional angiograms (ridicule stage). Violent opposition to this modality came in the late 1990s, when debates at the American College of Cardiology and AHA centered on the inappropriate advertising of these tests, rather than the science. Today, we are approaching the third stage, with the acceptance that cardiac CT has an important role in risk stratification (coronary artery calcification) and diagnosis of obstructive coronary artery disease (CT angiography).

As you will see, cardiac CT has matured significantly. It has become a powerful risk stratifying tool for the early detection of atherosclerosis, a possible substitute for coronary angiography or non-invasive exercise testing in certain clinical situations, and a powerful tool to image the heart for congenital heart disease, pre- and postelectrophysiologic testing and peripheral angiography. Future directions include possibly replacing some conventional catheterizations, and non-invasive tracking of atherosclerosis (progression/regression of either calcified plaque or non-calcified or "soft plaque"). The promise of CT includes non-invasive coronary plaque characterization, as well as accurate stenosis identification. It is highly likely that if these goals are obtained, CT coronary angiography may become the most valuable tool to evaluate the coronary arteries non-invasively. It is possible that direct non-invasive CT visualization of the arteries will partially replace both nuclear cardiology and diagnostic angiography in certain clinical situations, with a subsequent increase in coronary revascularizations. 


\section{References}

1. Boyd DP, Lipton MJ. Cardiac computed tomography. Proc IEEE 1982;71;298-307.

2. Moshage WEL, Achenbach S, Seese B, Bachmann K, Kirchgeorg M. Coronary artery stenoses: Threedimensional imaging with electrocardiographically triggered, contrast agent-enhanced, electron beam CT. Radiology 1995;196:707-714.

3. Budoff MJ, Mao SS, Zalace CP, Bakhsheshi H, Oudiz RJ. Comparison of spiral and electron beam tomography in the evaluation of coronary calcification in asymptomatic persons. Int J Cardiol 2001;77:181-188.

4. Budoff MJ, Achenbach S, Duerinckx A. Clinical Utility of Computed Tomography and Magnetic Resonance Techniques for Noninvasive Coronary Angiography. J Am Coll Cardiol 2003;42;1867-1878.

5. Achenbach S, Ulzheimer S, Baum U, et al. Non-invasive coronary angiography by retrospectively EcG-gated multislice spiral CT. Circulation 2000;102:2823-2828. 


\section{Acknowledgments}

I would like to first thank Bruce Brundage MD, without whom as a mentor and friend, I never would have gotten into this field. He was a true visionary, who 20 years ago was already foreseeing the day when cardiac CT would become a mainstream test in Cardiology, as it now finally is. I would also like to thank my colleagues (mostly the other contributors and editors of this book) and researchers (Drs Songshou Mao, Lu Bin, Junichiro Takasu and others) who have taught me more about cardiac CT than I will ever teach them. Without their dedication and commitment, we would never be looking at the wealth of knowledge and understanding we have today. I would also like to thank the vendors (of both CT and workstations), who have provided insight, support and scientific knowledge to get us to where we are today. When we started doing CT angiography in 1995, it took us 3 weeks to reconstruct these images, now it takes 30 seconds. Some specific people who have particularly helped me in this regard: DeAnn Haas (General Electric), Philip Prather (Phillips Medical Systems), Robb Young (Toshiba) as well as Robert Taylor (TeraRecon) and Tina and Jason Young (NeoImagery Technologies).

Most importantly, I would like to thank my family, who have put up with me writing or editing this book for the past 8 months, working at times when I should have been with them. Thank you, Vicky, Daniel, and Garrett. Your support has made this book possible.

Matthew J. Budoff, MD, FACC, FAHA

I would like to thank Matthew Budoff for introducing me to the art and science of cardiovascular CT, and having the vision to see the applications for a multitude of disciplines within Cardiovascular Medicine. Your intelligence and enthusiasm have truly moved the field in novel directions. I would also like to thank Songshou Mao for his great insights and expertise in defining cardiovascular CT techniques. To the Harbor-UCLA EBCT Center staff, thank you for your excellence in providing CT services. Thank you to my family for your encouragement throughout my career. Most of all, to Rosemary, Anna, and Laura, thank you for your love and support.

Jerold S. Shinbane, MD, FACC 


\section{Contents}

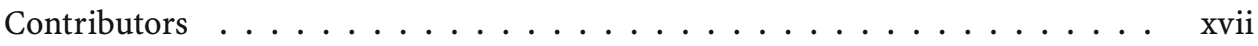

1 Computed Tomography

Matthew J. Budoff

2 Methodology for Image Acquisition

Songshou Mao and Jerold S. Shinbane . . . . . . . . . . . . . . . . . . .

3 Cardiac Anatomy by Computed Tomography

Philip H. Tseng and Matthew J. Budoff . . . . . . . . . . . . . . . . . . . .

4 Interpreting CT Angiography: Three-Dimensional

Reconstruction Techniques

Matthew J. Budoff

5 Assessment of Cardiac Structure and Function by X-ray

Computed Tomography

John A. Rumberger . . . . . . . . . . . . . . . . . . . . . . .

6 Assessment of Cardiovascular Calcium: Interpretation and Relevance of Calcium Scoring Relationship to Lipids and Other Cardiovascular Risk Factors

Harvey S. Hecht

7 Natural History and Impact of Interventions on Coronary Calcium

Paolo Raggi . . . . . . . . . . . . . . . . . . . . .

8 Extra-Coronary Calcium

David M. Shavelle and Junichiro Takasu . . . . . . . . . . . . . . . .

9 CT Coronary Angiography

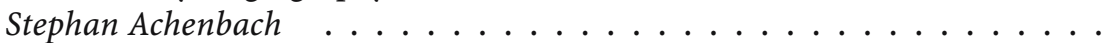

10 Coronary Angiography after Revascularization Axel Schmermund, Stefan Möhlenkamp, Thomas Schlosser, and

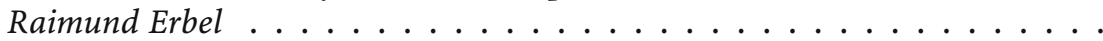

11 An Interventionalist's Perspective: Diagnosis of Cardiovascular Disease by CT Imaging

Jeffrey M. Schussler 
12 CT Imaging of Non-calcific Atherosclerotic Plaque with Cardiac Computed Tomography

M. Leila Rasouli . . . . . . . . . . . . . . . . . . . . . . . . . . 165

13 Peripheral Angiography

Khurram Nasir and Matthew J. Budoff . . . . . . . . . . . . . . . . . .

14 Aortic, Renal, and Carotid CT Angiography Matthew J. Budoff . . . . . . . . . . . . . . . . . . .

15 Cardiovascular Magnetic Resonance Imaging: Overview of Clinical Applications

Jerold S. Shinbane, Patrick M. Colletti, and Gerald M. Pohost . . . . . . . .

16 Congenital Heart Disease and Computed Tomography

Jamil AboulHosn and Ronald J. Oudiz . . . . . . . . . . . . . . . . . . .

17 Nuclear Cardiology and Cardiac Computed Tomography in Assessment of Patients with Known or Suspected Chronic Coronary Artery Disease Daniel S. Berman, Rory Hachamovitch, Leslee J. Shaw, Guido Germano, Nathan D. Wong and Alan Rozanski . . . . . . . . . . . . . . . .

18 CT Imaging: Cardiac Electrophysiology Applications Jerold S. Shinbane and Matthew J. Budoff . . . . . . . . . . . . . . . . . 261

Index $\ldots$

Various Cardiac CT Imagery on CD-ROM $\ldots \ldots$ Inside back cover 


\section{Contributors}

Jamil AboulHosn, MD

Ahmanson/UCLA

Adult Congenital Heart

Disease Center,

David Geffen School of

Medicine at UCLA,

Los Angeles, CA, USA

Stephan Achenbach, MD, FESC

Department of Internal Medicine II

University of Erlangen

Erlangen, Germany

Daniel S. Berman

Department of Imaging

Cedars-Sinai Medical Center

Los Angeles, CA, USA

Matthew J. Budoff, MD, FACC, FAHA

Los Angeles Biomedical Research

Institute

Harbor-UCLA Medical Center,

Torrance, CA, USA

Patrick M. Colletti, MD

Department of Radiology

USC Keck School of Medicine

LAC + USC Imaging Science Center

Los Angeles, CA, USA

Raimund Erbel, MD

Department of Cardiology

University Clinic Essen

Essen, Germany

Guido Germano, PhD, MBA

Artificial Intelligence in Medicine (AIM)

Program

Cedars-Sinai Medical Center

Los Angeles, CA, USA

Rory Hachamovitch, MD, MSC

Division of Cardiovascular Medicine,

USC Keck School of Medicine

Los Angeles, CA, USA
Harvey S. Hecht, MD, FACC

Cardiac Computed Tomography

Lenox Hill Heart and Vascular

Institute

New York, USA

Songshou Mao, MD

Department of Cardiology

Los Angeles Biomedical Research Institute

Harbor-UCLA Medical Center

Torrance, CA, USA

Stefan Möhlenkamp, MD

Department of Cardiology

Westdeutsches Herzzentrum Essen

Essen, Germany

Khurram Nasir, MD, MPH

Department of Cardiology

Johns Hopkins University

Baltimore, MD, USA

Ronald J. Oudiz, MD

Division of Cardiology

Harbor-UCLA Medical Center

Torrance, CA, USA

Gerald M. Pohost, MD, FACC, FAHA

Division of Cardiovascular Medicine

USC Keck School of Medicine

Los Angeles, CA, USA

Paolo Raggi, MD

Department of Cardiology

Tulane University School of

Medicine

New Orleans, LA, USA

M. Leila Rasouli, MD

Department of Cardiology

Harbor-UCLA Medical Center

Newport Coast, CA, USA 
Alan Rozanski, MD

Department of Medicine

St. Luke's Roosevelt Hospital Center

New York, NY, USA

John A. Rumberger, PhD, MD

Cardiovascular Disease

The Ohio State University

Dublin, Ohio, USA

Thomas Schlosser, MD

Department of Diagnostic and

Interventional Radiology and

Neuroradiology

University Clinic Essen

Essen, Germany

Axel Schmermund, MD

Internal Medicine and Cardiology

Cardioangiologisches Centrum

Bethanien

Frankfurt am Main, Germany

Jeffrey M. Schussler, MD, FACC, FSCAI

Cardiovascular Disease (Internal

Medicine)

Baylor University Medical Center

Dallas, Texas, USA

David M. Shavelle, MD

Division of Cardiology, Department of Medicine

Harbor-UCLA Medical Center

Torrance, CA, USA
Leslee J. Shaw, PhD

Department of Medicine

Cedars-Sinai Medical Center

Los Angeles, CA, USA

Jerold S. Shinbane, MD, FACC

Division of Cardiovascular

Medicine

USC Keck School of

Medicine

Los Angeles, CA, USA

Junichiro Takasu, MD, PhD

Department of Medicine

Harbor-UCLA Medical Center

UCLA School of Medicine,

Torrance, CA, USA

Philip H. Tseng, BS

Department of Cardiology

Los Angeles Biomedical Research

Institute

Harbor-UCLA Medical Center

Torrance, CA, USA

Nathan D. Wong, PhD

Heart Disease Prevention Program, Department Medicine

University of California Irvine

Irvine, CA, USA 